\title{
The Relationship between Supervisor Error Bearance and Employee Creativity: Perceived Supervisor Support as a Mediator and Proactive Personality as a Moderator
}

\author{
Mei-hua SHI ${ }^{1, a}$, Bao-cheng LIU ${ }^{2, b}$, Wei CHEN ${ }^{3, c}$, Guan-yi-tong ZHOU ${ }^{4, d}$, Wen-si \\ $\operatorname{LIN}^{5, e}$ \\ 1, 3, 4, 5 Macau University of Science and Technology, Avenida Wai Long, Taipa, Macau, China \\ ${ }^{2}$ Tianjin Foreign Studies University, No.117, Machang Road, Hexi District, Tianjin, China \\ atinyshi@126.com, ${ }^{b}$ liubaocheng@hotmail.com, cnoah.chan@163.com, ${ }^{\mathrm{d}} 7887950 @ q q . c o m$, \\ e23341333@qq.com
}

Keywords: Supervisor Error Bearance, Employee Creativity, Perceived Supervisor Support, Proactive Personality.

\begin{abstract}
Creativity is vital to enterprises and nearly every enterprise wants to have employees with high creativity. Researchers have explored many factors that would affect employee creativity. Our main contribution may lie on introduced "supervisor error bearance" as an antecedent variable to employee creativity. Meanwhile, employee perceived supervisor support was introduced as a mediator and employee proactive personality was introduced as a moderator which moderates the relationship between supervisor's error bearance and employee creativity via employee perceived supervisor support. Management implication is also discussed.
\end{abstract}

\section{Introduction}

"Employee creativity refers to the creation of valuable, useful new products, services, ideas, procedures, or processes by individuals working together in a complex social system [1]". Researchers have explored many factors that would affect employee creativity from individual aspects to social aspects. However, to our knowledge, supervisors' personal characteristics especially supervisors' inclusive ability to employees' error makings is seldom explored. From the definition of employee creativity, we can see that if supervisors want to have employees with creativity, they should encourage them to use different ways to work or to figure out new ideas boldly. All of employees' creativity behaviors may make errors. What's supervisors' attitude towards employees' error making? Can supervisors tolerate employees’ mistakes? Do supervisors’ personality especially error tolerating ability affects employee creativity? How? Thus, we introduce a new term "supervisor error bearance" to describe "supervisors' inclusive ability to employees' error making” in order to explore the relationship among them.

In this paper, we define supervisor error bearance as: supervisors' tolerable ability towards employees' error makings of which are not purposely made. In this definition, we should notice that employees' error makings we defined are not counterproductive work behaviors, and employees' error makings are not purposely made. Error bearance in this term is used to show supervisors' inclusive attitude towards employees' working methods.

As one of supervisor's leadership styles or ability, how supervisor error bearance affects employee creativity is becoming vital to the organizations. This paper explored the relationship between supervisor error bearance and employee creativity from individual aspect. Meanwhile, it introduces two variables: perceived supervisor support and proactive personality. Perceived supervisor support is used as a mediator which mediates the relationship between supervisor error bearance and employee creativity. Proactive personality is used as a moderator which moderates the mediated relationship between supervisor error bearance and employee creativity via proactive personality. Managerial implication is also given. Figure 1 is our conceptual model. 


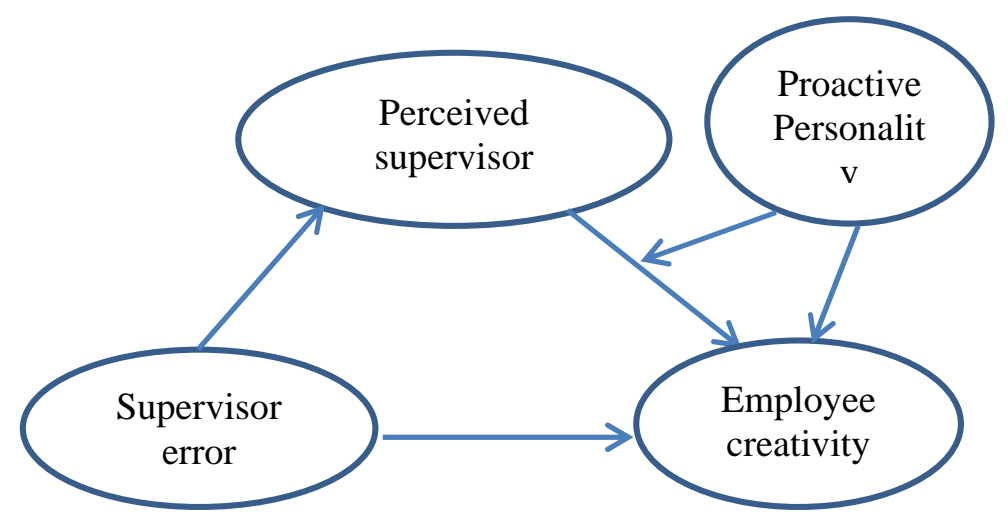

Fig.1 The conceptual model of the paper

\section{Research Literature and Hypotheses}

\section{Supervisor error bearance and employee creativity}

Errors have been studied by varies field including cognitive psychology and organizational behavior, of which most explored the negative aspect of error making and reasons for it and how to avoid making error. However, errors may be positive or beneficial to the organizations [2, 3]. According to Gary, supervisors need to change their attitudes towards error making or breaking the result-oriented atmosphere [4] and supervisors must become supportive to employees who make an error or two, otherwise, they will kill any passion employees may have [4]. Therefore, errors are not avoidable and should be expected [4]. Employees need to know that their supervisors will not "hang them out to dry" once an error is made [4]. Supervisors who want to have employees with creativity should give support to employees who make mistakes when they try to work efficiently or try to use other way to complete their jobs.

Supervisors who have high error bearance will make a harmonious environment to the supervisor-employee relations. Harmonious relationship between supervisors and employees will make both supervisors and employees work with pleasant feelings or have positive emotions. Employees with a happy mood will increase production and creativity, for positive emotions broaden people's thought and build their enduring personal resources ranging from physical and intellectual to social and psychological resources [5, 6]. Meanwhile, employees with a supervisor who is tolerable to employees' errors will be encouraged to take risks and persist with challenges $[7,8]$. They'd like to try new approaches, explore uncertain but potentially promising methods and also persevere in problem solving activities [7, 8]. Thus, we hypothesize that:

Hypothesis 1: Supervisor error bearance is positively related to employee creativity.

\section{Supervisor error bearance and employee perceived supervisor support}

How supervisors treat employees who make errors will go a long way in establishing whether the team becomes depressed and stagnant or action oriented and motivated [4]. Supervisors who have high tolerating personality will show more support (e.g. oral encouragement, formally protect and etc.) to employees who make errors during work. While supervisors who are intolerable (or have low tolerating personality) to employees' error makings will oppose to employees' error making which may be perceived from their gestures or attitudes (e.g. criticizing, showing indifference, undermining and etc). Supervisors' gestures or attitudes will be perceived by their employees. Through investigating 346 employee-supervisor dyads from diverse organizations, Pedro and Robert (2014) found that failure-related trust among subordinates and supervisors was positively related to perceived organizational support (POS) [9]. Employees who have the ability to perceive organizational support will definitely have the ability to perceive supervisor support. Therefore, we assume that supervisors who are tolerable to employees' errors will be perceived by their employees. The more supervisors use this strategy, the more chances will their employees perceived this support. Thus, we hypothesize that: 
Hypothesis 2: Supervisor error bearance is positively related to employee perceived supervisor support.

\section{Employee perceived supervisor support and employee creativity}

Supervisor support plays an important role in developing employees' perceptions of the organization. Employees who perceived supervisor support will work harder and may be more satisfied with their job. Therefore, perceived supervisor support is a very important variable influencing employees' job attitude and behavior. When a supervisor serves as a good role model, facilitates the goal-setting process, values employee contributions, and has confidence in the work group, perceived supervisor support for creativity is more likely to occur [10]. Thus, we hypothesize that:

Hypothesis 3a: Employee perceived supervisor support is positively related to employee creativity.

From hypothesis 12 , 3a, we already know supervisor error bearance is positively related to employee creativity, supervisor error bearance is positively related to employee perceived supervisor support, and employee perceived supervisor support is positively related to employee creativity. Furthermore, employees who perceived supervisors' error bearance behavior will feel supervisors' support, hence, employees are not afraid of being criticized or even fired by supervisors and want to try new ways to work, and therefore, their potentials are stimulated. Thus, we hypothesize that:

Hypothesis 3b: employee perceived supervisor support will partially mediate the relationship between supervisor error bearance and employee creativity.

\section{Employee's proactive personality and employee creativity}

The stimulating sources of new ideas reflect orientation. Employees with proactive personality are more change-oriented and self-initiated [11, 12, 13]. To them, actively respond to the coming information and opportunities are preferred [11, 12, 13]. It is much easier for them to better understand company politics, accept new ideas, and update their working skills [14, 15]. A recent model of work role performance identified individual proactive behavior as one of nine core work role behaviors [16].

Binnewies and his cooperators (2007) found that personal initiative boosted engagement in the beginning of the creative process and was positively related to creativity [18].Seibert et al. (2001) found that proactive personality was positively associated with individual's innovative behaviors, such as developing new ideas, easily taking the new methods into practice, thus showing innovation in one's job [17]. Furthermore, Kim and co-authors (2010) approved that proactive personality was positively associated with employee creativity [19]. Thus, we hypothesize that:

Hypothesis 4: Employee's proactive personality is positively related to employee creativity.

\section{Proactive personality as a moderator moderates the mediation relationship of supervisor error bearance and employee creativity via employee perceived supervisor support}

As we described before, compared to passive people who just adapt to their undesirable circumstances, people with proactive personality are more likely to initiate changes, take action, and persevere until meaningful change occurs in the achievement of their goals [10]. In hypothesis 3a, we have assumed that employee perceived supervisor support is positively related to employee creativity. From hypothesis 3b, we know employee perceived supervisor support will partially mediate the relationship between supervisor error bearance and employee creativity. Thus, we hypothesize that:

Hypothesis 5: Proactive personality will moderate the strength of the mediated relationship between supervisor error bearance and employee creativity via perceived supervisor support, such that this mediating effect is stronger under employee with high proactive personality than under employee with low proactive personality.

\section{Managerial Implications}

As supervisor error bearance has positive effect on employee creativity, supervisors should tolerate employees' error making (at limited level) and encourage them to take risk. Meanwhile, supervisors with error bearance attitude who want to inspire employees' creativity should make sure that 
employees perceived their support. Furthermore, organizations can select employees with proactive personality to positions that needs more challenge and creativity behavior.

\section{References}

[1] R.W. Woodman, J.E. Sawyer and R.W. Griffin: Toward a theory of organizational creativity. Academy of Management Review, 18(1993), p. 293-332.

[2] S.B. Sitkin: Learning through failure: The strategy of small losses, in: Organizational Learning, edited by M.D. Cohen and L.S. Sproull, Thousand Oaks, CA: Sage. (1996), p. 541-578.

[3] C. Van Dyck, M. Frese, M. Baer and S. Sonnentag: Organizational error management culture and its impact on performance: A two-study replication. Journal of Applied Psychology, 90 (2005), p. 1228-1240.

[4] G.A. Bielous: Create an atmosphere of blameless error. Supervision, 74 (2013), p. 23-26.

[5] B.L. Fredrickson and C. Branigan: Positive emotions broaden the scope of attention and thought-action repertoires. Cognition and Emotion, 19 (2005), p. 313-332.

[6] G. Martín-de Castro, M. Delgado-Verde, J.E. Navas-López and J. Cruz-González: The moderating role of innovation culture in the relationship between knowledge assets and product innovation. Technological Forecasting and Social Change, 80 (2013), p. 351-363.

[7] M. Baer and G.R. Oldham: The curvilinear relation between experienced creative time pressure and creativity: Moderating effects of openness to experience and support for creativity. Journal of Applied Psychology, 91 (2006), p. 963-970.

[8] N. Pedro and E. Robert: Perceived organizational support and risk taking. Journal of Managerial Psychology, 29, (2014), p. 187-205.

[9] T.M. Amabile, R.M. Burnside and S. S. Gryskiewicz: User's manual for KEYS: Assessing the climate for creativity: A survey from the Center for Creative Leadership. Greensboro, NC: Center for Creative Leadership (1999).

[10] J.M. Crant: Proactive behavior in organizations. Journal of Management, 26 (2000), p. 435-462. [11]N. Li, J. Liang and J.M. Crant: The role of proactive personality in job satisfaction and organizational citizenship behavior: A relational perspective. Journal of Applied Psychology, 95 (2010), p. 395-404.

[12] G.H. Huang, H.H. Zhao, X.Y. Niu and S.J. Ashford: Reducing job insecurity and increasing performance ratings: Does impression management matter? Journal of Applied Psychology, 98 (2013), p. 852-862.

[13] G.J. Greguras and J.M. Diefendorff: Why does proactive personality predict employee life satisfaction and work behaviors? A field investigation of the mediating role of the self-concordance model. Personnel Psychology, 63 (2010), p. 539-560.

[14] S.E. Seibert, J.M. Crant and M.L. Kraimer: Proactive personality and career success. Journal of Applied Psychology, 84 (1999), p. 416-427.

[15]M.A. Griffin, A. Neal and S.K. Parker: A new model of work role performance: Positive behavior in uncertain and interdependent contexts. Academy of Management Journal, 50 (2007), p. 327-347.

[16] S.E. Seibert, M.L. Kraimer and R.C. Liden: A social capital theory of career success. Academy of Management Journal, 44 (2001), p. 219-237.

[17] S.E. Seibert, M.L. Kraimer and J.M. Crant: What do proactive people do? A longitudinal model linking proactive personality and career success. Personnel Psychology, 54 (2001), p. 845-874.

[18] C. Binnewies, S. Ohly and S. Sonnentag: Taking personal initiative and communicating about ideas: What is important for the creative process and for idea creativity? European Journal of Work and Organizational Psychology, 16 (2007), p. 432-455.

[19]T. Kim, A.Y. Hon and L. Deog-Ro: Proactive personality and employee creativity: The effects of job creativity requirement and supervisor support for creativity. Creativity Research Journal, 22 (2010), p. 37-45. 